\title{
Participation in a Community-Based Women's Health Education Program and At-Risk Child Development in Rural Kenya: Developmental Screening Questionnaire Results Analysis
}

Megan S. McHenry, ${ }^{a, b}$ Lauren Y. Maldonado, ${ }^{a, c}$ Ziyi Yang, $^{b}$ Gertrude Anusu, ${ }^{a}$ Evelyn Kaluhi, ${ }^{a}$ Astrid Christoffersen-Deb, ${ }^{a, d, e^{*}}$ Julia J. Songok, ${ }^{a, f^{*}}$ Laura J. Ruhla, ${ }^{a, b} f^{*}$

\section{Key Findings}

- Infants in Chamas had a lower likelihood of at-risk development compared to those in the control group. Older infant age at time of screening and having natural or uncovered walls was also associated with lower odds of at-risk development.

- Our findings offer evidence to support that by addressing health literacy, providing community in a supportive environment, and offering a means to combat social determinants of child developmental delays, the Chamas for Change intervention may help protect children from developmental delays in this resource-limited setting in Kenya.

\section{Key Implications}

- When looking to revise current strategies to help protect children from developmental delay in this setting, policy makers should consider interventions that leverage existing resources to ensure their sustainability.

\footnotetext{
${ }^{a}$ Academic Model Providing Access to Healthcare (AMPATH), Eldoret, Kenya.

${ }^{\mathrm{b}}$ Indiana University School of Medicine, Indianapolis, IN, USA.

'Massachusetts General Hospital, Departments of Medicine and Pediatrics, Boston, MA, USA.

dUniversity of British Columbia, Department of Obstetrics and Gynecology, Vancouver, Canada.

e University of Toronto, Department of Obstetrics and Gynecology, Toronto, Canada.

${ }^{f}$ Moi University College of Health Sciences, Department of Child Health and Paediatrics, Eldoret, Kenya.

${ }^{*}$ Co-principal investigators on this study and share equal authorship on this article. Correspondence to Megan McHenry (msuhl@iu.edu).
}

\section{ABSTRACT}

Background: Over $43 \%$ of children living in low- and middleincome countries are at risk for developmental delays; however, access to protective interventions in these settings is limited. We evaluated the effect of maternal participation in Chamas for Change (Chamas) - a community-based women's health education program during pregnancy and postpartum - and risk of developmental delay among their children in rural Kenya.

Methods: We analyzed developmental screening questionnaire (DSQ) data from a cluster randomized controlled trial in Trans Nzoia County, Kenya (ClinicalTrials.gov, NCT03187873). Intervention clusters (Chamas) participated in community health volunteer-led, group-based health lessons twice a month during pregnancy and postpartum; controls had monthly home visits (standard of care). We screened all children born during the trial who were alive at 1-year follow-up. We labeled children with any positive item on the DSQ as "at-risk development." We analyzed data using descriptive statistics and multilevel regression models ( $\alpha=.05)$; analyses were intention-totreat using individual-level data.

Results: Between November 2017 and March 2018, we enrolled 1,920 pregnant women to participate in the parent trial. At 1-year follow-up, we screened 1,273 (689 intervention, 584 control) children born during the trial with the DSQ. Intervention mothers had lower education levels and higher poverty likelihood scores than controls $(P<.001$ and $P=.007$, respectively). The overall rate of at-risk development was $3.5 \%$. Children in Chamas clusters demonstrated significantly lower rates of at-risk development than controls $(2.5 \%$ vs. $4.8 \%, P=.025)$. Adjusted analyses revealed lower odds for at-risk development in the intervention arm $(O R=0.50 ; 95 \%$ confidence interval $=0.27,0.94)$.

Conclusions: Maternal participation in a community-based women's health education program was associated with lower rates of at-risk development compared to the standard of care. Overall, rates of at-risk development were lower than expected for this population, warranting further investigation. Chamas may help protect children from developmental delay in rural Kenya and other resource-limited settings.

\section{INTRODUCTION}

arly childhood development (ECD) lays the foundation upon which every individual's cognitive, social, 
and emotional abilities are built. As such, investing in ECD not only benefits individuals but also boosts shared prosperity and helps eliminate extreme poverty. ${ }^{1,2}$ However, recent data suggest that more than $43 \%$ of children under age 5 years living in low- and middle-income countries (LMICs) are at risk for developmental delays. ${ }^{3}$ Among children at risk, more than $60 \%$ reside in sub-Saharan Africa. ${ }^{4}$ This inequity perpetuates intergenerational cycles of poverty, particularly in rural communities where children are often denied equal access to resources and opportunities that nurture ECD.

The World Health Organization (WHO) estimates that $45 \%$ of children under age 5 years in Kenya are at risk for developmental delays (56\% rural, $25 \%$ urban), translating to an estimated $138 \%$ loss in annual adult wages. ${ }^{5}$ Multifaceted challenges have limited the success of recent efforts (e.g., government policies, school-based programming) to bolster ECD. These challenges include inadequate financial investment in early education, poor access to health services that protect against known risk factors (e.g., malnutrition, recurrent and/or chronic infections), and limited awareness of the deleterious role of chronic stress (e.g., harsh punishment) on development. ${ }^{6}$ Moreover, few policies focused on ECD target the first 1,000 days of life-a critical period during which the brain undergoes rapid change and establishes a framework for lifelong learning. ${ }^{7}$ Inadequate antenatal care, ${ }^{8-10}$ malnutrition, ${ }^{1}$ and maternal depression, ${ }^{11}$ during this period can also have long-standing negative consequences. ${ }^{1,7,12}$ Effective interventions that protect against developmental delays within rural, resource-limited settings are urgently needed to address these disparities.

In 2012, the Academic Model Providing Access to Healthcare partnership and Republic of Kenya Ministry of Health established the Chamas for Change (Chamas) program to help improve maternal, newborn, and child health (MNCH) in rural western Kenya. ${ }^{13,14}$ Chamas is a longitudinal program that supports women during pregnancy and for the first 1,000 days of the infants' lives with community-driven, group-based health education. Importantly, this intervention integrates known strategies to improve outcomes for women and infants, including ECD, while leveraging existing resources in rural Kenyan communities. A pilot study evaluating the first year of this program demonstrated significant associations between participation and the likelihood of practicing positive $\mathrm{MNCH}$ behaviors, including attending adequate antenatal care and exclusively breastfeeding. ${ }^{14,15}$

To test our hypothesis that maternal participation in Chamas improved MNCH outcomes, including ECD, we conducted a cluster-randomized controlled trial in Trans Nzoia County, Kenya. In this article, we report results from developmental screening questionnaires (DSQ) completed on children born during the trial at 1-year follow-up.

\section{METHODS}

\section{Study Design and Setting}

We analyzed DSQ data from a 2-arm cluster randomized controlled trial in 74 communities across 4 subcounties (Cherangany, Saboti, Kwanza, and Kiminini) in Trans Nzoia County, Kenya. We chose a cluster-randomized design to minimize contamination due to intervention exposure between neighboring villages. We defined clusters as community health units-geographically defined health service delivery areas for populations of 5,000 people overseen by community health volunteers (CHVs). ${ }^{16}$ We randomized community health units 1:1 (non-stratified, non-matched) using a simple random allocation sequence to participate in Chamas (intervention) or receive recommended monthly home visits from CHVs (standard of care) for 1 year. Data collectors, analysts, and investigators were masked to cluster allocation throughout the study; however, trial arms were identifiable to participants and CHVs by design.

We selected Trans Nzoia due to its geographic and socioeconomic diversity, as well as the presence of longstanding collaborations between the Government of Kenya, Ministry of Health, and Academic Model Providing Access to Healthcare. Trans Nzoia has nearly 1 million residents who largely subside on agricultural businesses and raising livestock. Moreover, health indicators for mothers and infants are consistently poorer than national estimates, reflecting a need for increased attention to $\mathrm{MNCH}$ policy and programming. ${ }^{17}$

\section{Procedures}

Pregnant women presenting to the local health facility for their first antenatal care visit by 32 weeks' gestation were eligible to participate in the parent trial. Participants were allocated to each arm by their randomized community of residence. At approximately 1 -year follow-up (i.e., 12 months of Chamas participation, initiating prenatally), we screened all children born during the trial with the DSQ, with no additional exclusion criteria. Data collectors traveled to participant homes to collect in-person data using electronic tabletbased, structured questionnaires. We synced data at the end of each collection day to a central,

A pilot study
evaluating the
first year of
Chamas
demonstrated
significant
associations
between
participation and
the likelihood of
practicing positive
MNCH behaviors,
including
attending
adequate
antenatal care
and exclusively
breastfeeding.


encrypted server. Research assistants made 3 attempts to contact participants over a 2-week period before declaring them lost to follow-up.

Intervention details are described in our protocol (ClinicalTrials.gov NCT03187873) ${ }^{18}$ and previous publications. A detailed summary of the intervention is noted within Supplement 1. Briefly, Chamas clusters convened twice per month for 12 months for group-based health lessons led by CHVs. Each group typically included 15-20 women, their infants, 2 CHV facilitators, and 2 postmenopausal mentor mothers. Health lessons during the first year of the program promoted positive $\mathrm{MNCH}$ behaviors during pregnancy (e.g., attending adequate antenatal care) and infancy (e.g., exclusively breastfeeding and immunizing infants). Women were also introduced to topics contributing to risk factors and social determinants associated with developmental delays such as infant growth monitoring and nutrition, ${ }^{1,19}$ disease prevention, ${ }^{20,21}$ childhood harsh punishment, ${ }^{22}$ and parental stress. ${ }^{14,23}$ These and other developmentally focused lessons are largely addressed during the second and third years of the curriculum. After each lesson, women were also invited to participate in an optional microfinance program called Group Integrated Savings for Health and Empowerment (GISHE). Participation in GISHE was completely optional so as not to deter women without financial means to contribute to group savings from joining Chamas. Women who chose to participate were encouraged to use savings and loans generated by GISHE to enroll in health insurance, pay for school fees and educational materials, and/or start small businesses.

Control clusters had monthly CHV home visits during the antenatal and postpartum period as recommended by the current standard of care. ${ }^{25}$ During monthly visits, CHVs aimed to collect basic health information, recognize antenatal and early postpartum danger signs, aid in infant growth monitoring, and refer individuals requiring services to health facilities. Further, CHVs were expected to encourage women to adopt the same positive health behaviors emphasized in Chamas, namely: attending antenatal care, delivering in health facilities, exclusively breastfeeding, adopting modern methods of contraception, fully immunizing infants, and ensuring adequate infant nutrition.

\section{Study Outcomes}

Our primary outcome of interest was the rate of development" across study arms. defined "at-risk development" as any child who screened positive in 1 or more functional domains on the DSQ. We selected the DSQ as it has been validated for use among children less than aged 2 years in an LMIC. ${ }^{26}$ Of note, this tool is a screening questionnaire and not a diagnostic neurodevelopmental assessment. This validated questionnaire asks parents to report responses to 8 dichotomous "yes/no" questions in each of the following functional domains, which are specific to age (in months): gross motor, fine motor, vision, hearing, cognition, socialization, behavior, and speech. A list of the DSQ testing items can be viewed within Supplement 2. We considered any "yes" response a positive screen. Data collectors used ageappropriate DSQs for each infant by imposing an electronic checkpoint in RedCap (coded by birthdate). Lastly, if participants carried a multiple gestation pregnancy, we conducted independent questionnaires for each child.

To assess modifying effects of covariates, we collected baseline sociodemographic and reproductive health data for all participants. We used the validated Kenya 2015 Poverty Probability Index (PPI) tool to calculate individual poverty likelihood scores using the National Poverty Line Look-Up Table. ${ }^{27}$ This tool comprises 10 questions that assess sociodemographic factors such as county of residence, household education level, housing materials, and recent household purchases. Answers are coded using a numeric scoring system and summarized in a composite PPI score, which can be converted to a percentage value for poverty probability. We additionally collected end-line data on participant attitudes toward harsh punishment, infant birth weight, and age of first mixedfeeding as these variables have demonstrated significant associations with developmental delay outcomes in previous studies. ${ }^{22,23,29}$ We used a single item from the validated ISPCAN child abuse screening tool, parent version, to assess harsh punishment. ${ }^{30}$ Responses were collected using a 5-point Likert scale, ranging from "strongly disagree" to "strongly agree."

\section{Statistical Analysis}

The sample size calculation was based on the study's primary outcome, which was facilitybased births. ${ }^{14}$ This calculation used methods described by Rutterford et al. for a proposed mixedeffects regression analysis ${ }^{31}$ using derived baseline estimates. ${ }^{14,32}$ We assumed a mean cluster size of 20 individuals, with 77 clusters (equally allocated between arms) and intracluster correlation 
coefficient of 0.44 (based on pilot data ${ }^{14}$ ), and $20 \%$ attrition. With these assumptions, a total of 1,280 individuals would be needed to detect a $4.7 \%$ difference on the risk difference scale with $80 \%$ power at a (2-tailed) significance level of .05 . A total of $1,273(66.3 \%)$ of participants completed the study at 12-month follow-up with DSQ data: we included 689 individuals from 37 clusters in the intervention (69.2\%) and 584 individuals from 37 clusters in the control $(63.2 \%)$ arms for analysis.

We assessed individual-level outcomes on all participants with complete DSQ data at 12months follow-up. We used an intention-to-treat approach by evaluating all intervention participants, regardless of Chamas attendance. We summarized participant characteristics in a tabular form. We calculated frequencies and percentages for categorical variables, as well as means and standard deviations for continuous variables. We compared proportions using chi-squared tests and means using independent t-tests.

We compared proportions of at-risk development among children within each study arm using chi-square tests. We used simple descriptive statistics to determine DSQ testing items and domains for which children most commonly screened positive. We reviewed available sociodemographic as well as endline variables and identified potential confounders using clinical judgment and evidence from the literature. We performed a univariate analysis with each identified variable and included those demonstrating statistical significance $(P<.05)$ or clinical meaning in our adjusted multivariate logistic regression model. We reported overall tests for each variable as well as estimated odds ratios with their 95\% confidence intervals (CI). For households with twin children, we included DSQ data from the twin screened first in our regression model to limit bias introduced from duplicating covariate data from the same household and mother.

We decided a priori to restrict analyses solely to participants with both complete DSQ data and complete PPI data. We disaggregated items within the PPI to appropriately adjust for specific confounding variables known to impact child development (e.g., primary caregiver education level, head of household education level, housing materials). ${ }^{32,33}$ We conducted all statistical analyses in SAS 9.4 (SAS Institute, Cary, NC) statistical software and with $\alpha$ set to .05.

\section{Ethical Considerations}

We prospectively registered the parent trial with ClinicalTrials.gov (NCT03187873). Our study received ethics approval from the Institutional Research Ethics Committee at Moi Teaching and Referral Hospital and Moi University (IREC/2018/ 269) and the Office of Research Administration at Indiana University (1905296355). We obtained written informed consent from participants before data collection.

\section{Role of the Funding Source}

The funders had no role in the research design, collection, analysis, or interpretation of data, writing this report, or the decision to submit this manuscript for publication. The corresponding author had full access to all data in the study as well as final responsibility for the decision to submit this manuscript for publication.

\section{RESULTS}

Between November 27, 2017, and March 8, 2018, we enrolled 1,920 pregnant women from 74 communities to participate in the parent trial. At 1-year follow-up, we screened 1,273 (689 intervention, 584 control) of their children with the DSQ (Figure). Among those without DSQ data, 36 children in the intervention arm and 42 children in the control arm died before follow-up. Lastly, all 12 twin pairs in our study cohort had concurrent DSQ screening results between the twins.

Table 1 summarizes sociodemographic data for our study population ( $\mathrm{N}=1,273)$. Among included households, the mean child age was 10.9 months (standard deviation [SD]: 2.3) and maternal age was 26.8 years (SD: 6.4 ). The majority of mothers were married $(83.8 \%, \mathrm{n}=1,067)$ and unemployed $(63.0 \%, n=802)$. Overall, arms were fairly balanced; however, controls had more household members educated beyond primary school (41.1\% vs. 37.6\%; $P<.001)$ and a lower poverty likelihood $(29.0 \%$ vs. $32.0 \% ; P=.007)$ compared to intervention participants. Participants lost to follow-up were similar in number across study groups and attrition was not significantly associated with sociodemographic characteristics.

The overall rate of at-risk development among our study cohort was 3.5\% $(n=45)$. When divided into study groups, we observed a significantly lower rate of at-risk development in the intervention $\operatorname{arm}(2.5 \%$ vs. $4.8 \%, P=.025)$. We noted variable rates of at-risk development across child age (in months) at the time of screening (Table 2). The only significantly different rate between study arms, however, occurred at 8 months of age (10\% (4/40) control vs. $0 \%(0 / 46)$ intervention,

\section{We observed a significantly lower rate of at-risk development in the intervention arm (2.5\%) compared to the control arm (4.8\%).}


FIGURE. Cluster-Randomized Controlled Trial Profile and Study Inclusion Criteria of Maternal Participation in a Community-Based Women's Health Education Program in Rural Kenya

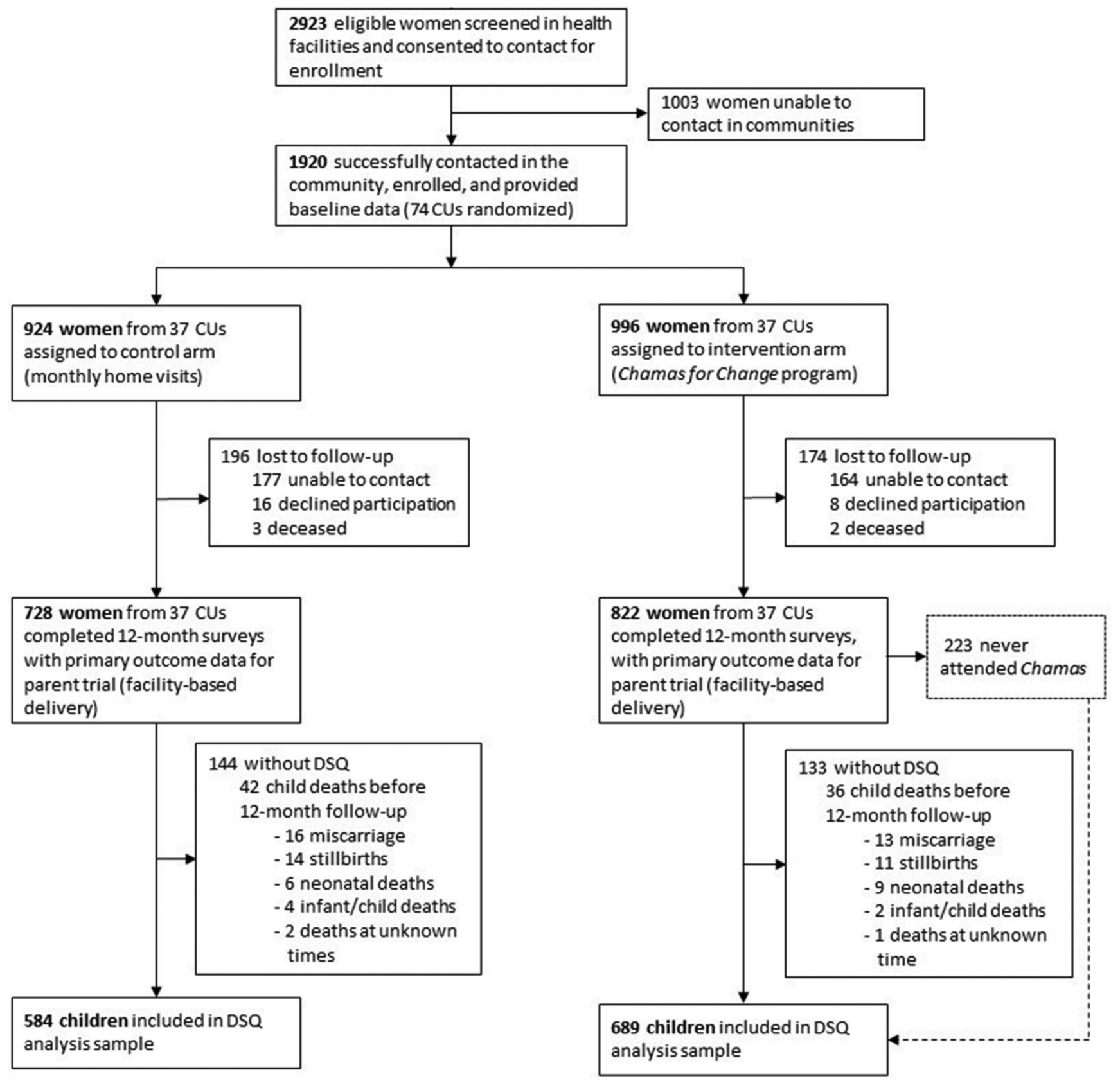

Abbreviations: CUs, community health units; DSQ, developmental screening questionnaire; Chamas, Chamas for Change Program.

$P=.043)$. The highest proportion of positively screened items pertained to the speech $(33.7 \%$, 30/89); gross motor (18.0\%, 16/89); and cognition (11.2\%, 10/89) domains. All remaining domainsfine motor, vision, hearing, socialization, and behavior-individually comprised no more than $4.5 \%-10.1 \%$ of remaining positive screening items.

We recorded outcomes on maternal attitudes toward harsh punishment, age of first mixed- 
TABLE 1. Characteristics of Women Included in a Cluster-Randomized Study on the Effect of Maternal Participation in a Women's Health Education Intervention on Early Childhood Development, Tranz Nzoia County, Kenya

\begin{tabular}{|c|c|c|c|c|}
\hline & Total $(\mathrm{N}=1,273) \mathrm{N}(\%)$ & Intervention (n=689) $\mathbf{n}(\%)$ & Control ( $n=584)$ n (\%) & P Value \\
\hline Child's age, months, mean (SD) & $10.9(2.3)$ & $11.2(2.4)$ & $10.5(2.2)$ & $<.001$ \\
\hline Mother's age, years, mean (SD) & $26.8(6.4)$ & $27.0(6.6)$ & $26.7(6.1)$ & .341 \\
\hline \multicolumn{5}{|l|}{ Categorized mother's age, years } \\
\hline$<18$ & $48(3.8)$ & $32(4.8)$ & $16(2.8)$ & \\
\hline $18-24$ & $462(36.8)$ & $240(35.8)$ & $222(38.1)$ & \\
\hline $25-32$ & $487(38.8)$ & $259(38.6)$ & $228(39.2)$ & \\
\hline$>32$ & $256(20.4)$ & $140(20.9)$ & $116(19.9)$ & .266 \\
\hline Missing data (n) & 20 & 18 & 2 & \\
\hline \multicolumn{5}{|l|}{ Marital status } \\
\hline Single/divorced/separation/widowed & $206(16.2)$ & $117(17.0)$ & $89(15.2)$ & \\
\hline Married & $1067(83.8)$ & $572(83.0)$ & $495(84.8)$ & .401 \\
\hline \multicolumn{5}{|l|}{ Employment status } \\
\hline Unemployed & $802(63.0)$ & $437(63.4)$ & $365(62.5)$ & \\
\hline Temporary work & $74(5.8)$ & $41(6.0)$ & $33(5.7)$ & \\
\hline Self-employed/permanently employed & $397(31.2)$ & $211(30.6)$ & $186(31.9)$ & .885 \\
\hline \multicolumn{5}{|l|}{ Highest educational level of household head* } \\
\hline Pre-primary/none/other & $181(14.3)$ & $87(12.7)$ & $94(16.1)$ & \\
\hline Primary & $592(46.6)$ & $342(49.9)$ & $250(42.8)$ & \\
\hline Secondary/post-primary/ vocational & $391(30.8)$ & $218(31.9)$ & $173(29.6)$ & \\
\hline College or higher & $106(8.4)$ & $39(5.7)$ & $67(11.5)$ & \\
\hline Missing data (n) & 3 & 3 & 0 & $<.001$ \\
\hline \multicolumn{5}{|l|}{ Highest educational level of any member ${ }^{a}$} \\
\hline Pre-primary/none/other & $103(8.2)$ & $44(6.5)$ & $59(10.1)$ & \\
\hline Primary & $485(38.5)$ & $268(39.6)$ & $217(37.2)$ & \\
\hline Secondary/post-primary/vocational & $468(37.1)$ & $272(40.2)$ & $196(33.6)$ & \\
\hline College or higher & $205(16.3)$ & $93(13.7)$ & $112(19.2)$ & .002 \\
\hline Missing data (n) & 12 & 12 & 0 & \\
\hline \multicolumn{5}{|l|}{ Household food access (during last 7 days) ${ }^{a}$} \\
\hline Bread & $834(65.8)$ & $439(64.3)$ & $395(67.6)$ & .209 \\
\hline Missing data (n) & 6 & 6 & 0 & \\
\hline Meat/fish & $924(72.8)$ & 488 (71.2) & $436(74.7)$ & .173 \\
\hline Missing data (n) & 4 & 4 & 0 & \\
\hline Bananas & $782(62.0)$ & $405(59.6)$ & $377(64.8)$ & .057 \\
\hline Missing data (n) & 11 & 9 & 2 & \\
\hline \multicolumn{5}{|l|}{ Household items ${ }^{a}$} \\
\hline Towels & 761 (59.9) & $398(58.0)$ & $363(62.2)$ & .134 \\
\hline Missing data (n) & 3 & 3 & 0 & \\
\hline
\end{tabular}


TABLE 1. Continued

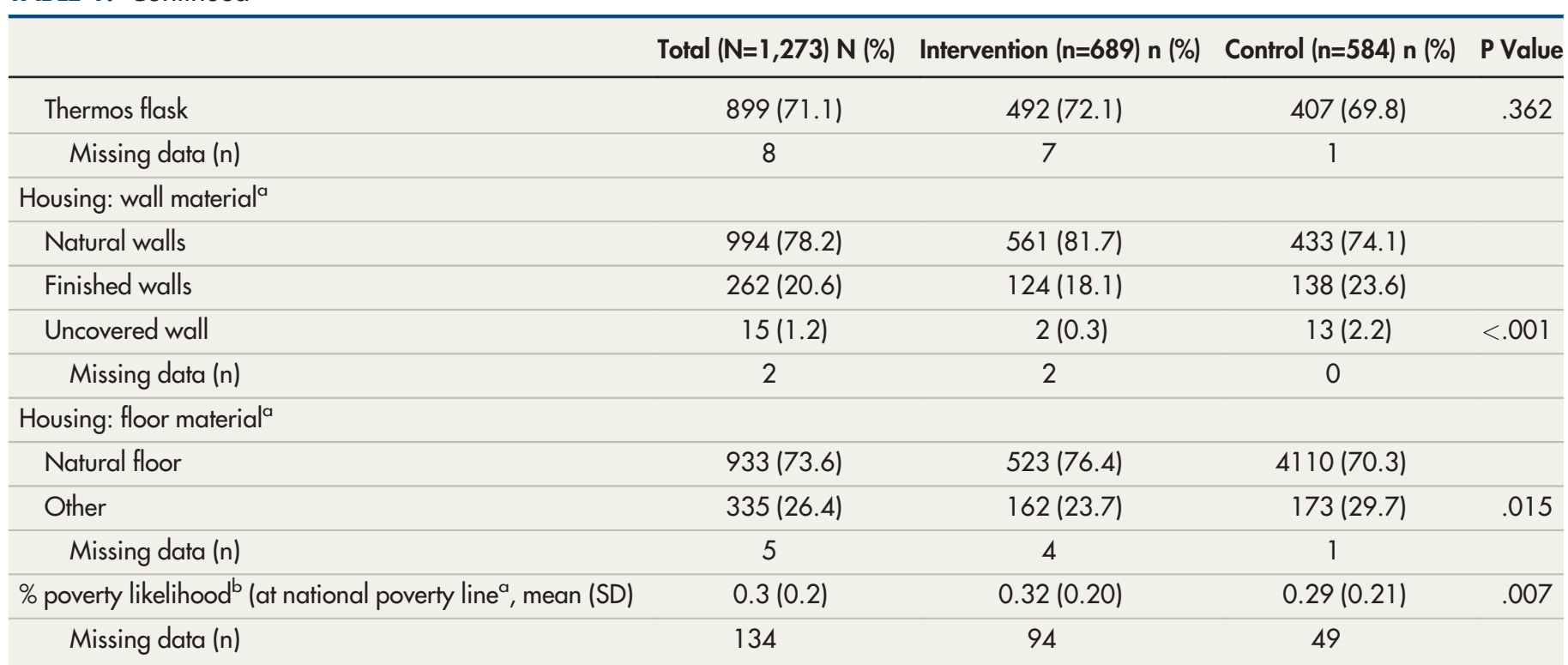

Abbreviation: SD, standard deviation.

Indicates variables included within the poverty probability index.

${ }^{b}$ The $\%$ poverty likelihood was derived based on the participants who had non-missing values on variables with ${ }^{a}$ in the table. We excluded 6 intervention and 6 control second-born twins among live dyads assessed.

TABLE 2. Rates of Child At-Risk Development, by Age and Study Group, in a Cluster-Randomized Study on the Effect of Maternal Participation in a Women's Health Education Intervention on Early Childhood Development, Tranz Nzoia County, Kenya

\begin{tabular}{llcc}
\hline Child Age (Months) $(\mathrm{N}=1,273)$ & Intervention & Control & P Value \\
\hline $1(\mathrm{~N}=5)$ & $0 / 2$ & $2 / 3(66.7 \%)$ & .400 \\
\hline $2(\mathrm{~N}=5)$ & $0 / 2$ & $0 / 3$ & - \\
\hline $3(\mathrm{~N}=8)$ & $0 / 5$ & $1 / 3(33.3 \%)$ & .375 \\
\hline $4(\mathrm{~N}=6)$ & $1 / 3(33.3 \%)$ & $1 / 3(33.3 \%)$ & 1.000 \\
\hline $5(\mathrm{~N}=9)$ & $0 / 6$ & $0 / 3$ & - \\
\hline $6(\mathrm{~N}=6)$ & $2 / 2(100.0 \%)$ & $3 / 4(75.0 \%)$ & 1.000 \\
\hline $7(\mathrm{~N}=55)$ & $2 / 29(6.9 \%)$ & $3 / 26(11.5 \%)$ & .659 \\
\hline $8(\mathrm{~N}=86)$ & $0 / 46$ & $4 / 40(10.0 \%)$ & .043 \\
\hline $9(\mathrm{~N}=132)$ & $2 / 59(3.4 \%)$ & $4 / 73(5.5 \%)$ & .691 \\
\hline $10(\mathrm{~N}=169)$ & $0 / 78$ & $4 / 91(4.4 \%)$ & .125 \\
\hline $11(\mathrm{~N}=243)$ & $1 / 114(0.9 \%)$ & $1 / 129(0.8 \%)$ & 1.000 \\
\hline $12(\mathrm{~N}=236)$ & $3 / 114(2.6 \%)$ & $3 / 122(2.5 \%)$ & 1.000 \\
\hline $13(\mathrm{~N}=169)$ & $2 / 120(1.7 \%)$ & $2 / 49(4.1 \%)$ & .580 \\
\hline $14(\mathrm{~N}=102)$ & $1 / 73(1.4 \%)$ & $0 / 29(0)$ & 1.000 \\
\hline $15(\mathrm{~N}=42)$ & $3 / 36(8.3 \%)$ & $0 / 6$ & 1.000 \\
\hline TOTAL & $17 / 689(2.5 \%)$ & $28 / 584(4.8 \%)$ & 0.025
\end{tabular}


feeding, and infant birthweight to adjust for their modifying effects on at-risk development. Mothers in the intervention arm more commonly agreed or strongly agreed with the use of physical punishment to discipline their children $(80.6 \%$ vs. $71.1 \%$; $P<.001)$. Mean infant birthweight differed slightly between study arms, however, both were clinically normal $(3.5 \mathrm{~kg}$ control vs. $3.4 \mathrm{~kg}$ intervention, $P=.036)$. Lastly, mothers in the intervention arm more commonly delayed mixed feedings after 3 months of age compared to controls $(80.1 \%$ vs. 75.4\%; $\mathrm{n}=1260 ; P=.049)$.

Multivariate logistic regression models demonstrated randomized study group $(P=.03)$, housing wall material $(P=.018)$, and child's age (in months) at screening $(P<.001)$ were significantly associated with likelihood of at-risk development er odds of at-risk development compared to controls $(\mathrm{OR}=0.50 ; 95 \% \mathrm{CI}=0.27,0.94)$ (Table 4). Participants with natural or uncovered walls demonstrated lower odds of at-risk development than those with finished walls ( $\mathrm{OR}=0.27 ; 95 \% \mathrm{CI}=0.09$, 0.80 ). Older infant age (in months) at the time of screening was also associated with a protective effect $(\mathrm{OR}=0.82 ; 95 \% \mathrm{CI}=0.73,0.92)$.

\section{DISCUSSION}

In 2015, the inclusion of ECD in the United Nation's Sustainable Development Goals (SDGs) was a landmark in the history of global policy surrounding this issue. Protecting, supporting, and (Table 3). Specifically, infants in Chamas had low-

promoting ECD is essential to accomplishing the first SDG, "to ensure that all human beings can fulfill their potential in dignity and equality." 34 Despite invigorated efforts and national commitments to support ECD, however, programs globally remain challenged by multi-factorial obstacles including inadequate and uncertain funding, inefficient resource allocation, and persistent health disparities. ${ }^{35}$ Moreover, recent investments in subSaharan Africa have largely focused on bolstering early education for children aged 4-5 years; while important, these strategies miss a critical window to intervene during the first 1,000 days of life. ${ }^{36,37}$ In this context, we rigorously evaluated the effect of a community-based women's health education program on at-risk development among children in rural Kenya. Our intention-to-treat analysis using a large sample from a geographically diverse catchment demonstrated a significant protective association between Chamas participation and atrisk development. Specifically, infants in Chamas demonstrated half the odds of at-risk development compared to those whose mothers received Ministry of Health recommended home visits.

The Chamas model embraces a multipronged approach to enhancing MNCH outcomes, including ECD. By providing women with opportunities to gain health literacy in a peer supportive environment, Chamas empowers women with both knowledge and community to improve outcomes for themselves and their infants during a critical developmental period. Further, among a subset

TABLE 3. Factors Associated With Child At-Risk Development in a Cluster-Randomized Study on the Effect of Maternal Participation in a Women's Health Education Intervention on Early Childhood Development, Tranz Nzoia County, Kenya

\begin{tabular}{lccc}
\hline Factor & Degrees of Freedom & Wald Chi-square Test Statistic & P Value \\
\hline Study randomization (intervention vs. control) & 1 & 4.72 & .030 \\
\hline Categorized mother's age in years & 3 & 0.98 & .807 \\
\hline Marital status & 1 & 0.11 & .739 \\
\hline Employment status & 2 & 4.51 & .105 \\
\hline Highest educational level of household head & 3 & 4.81 & .186 \\
\hline Housing-wall material & 1 & 5.56 & .018 \\
\hline Housing-floor material & 1 & 3.74 & .053 \\
\hline Age of mixed feeding & 1 & 1.96 & .162 \\
\hline Attitudes towards harsh punishment & 2 & 1.65 & .437 \\
\hline Child's birth weight in kilograms & 1 & 3.54 & .060 \\
\hline Child's age in months & 1 & 12.52 & $<.001$
\end{tabular}

\section{Chamas empowers women with both knowledge and community to improve outcomes for themselves and their infants during a critical developmental period.}


TABLE 4. Factors Associated With Child At-Risk Development in a Cluster-Randomized Study on the Effect of Maternal Participation in a Women's Health Education Intervention on Early Childhood Development, Tranz Nzoia County, Kenya

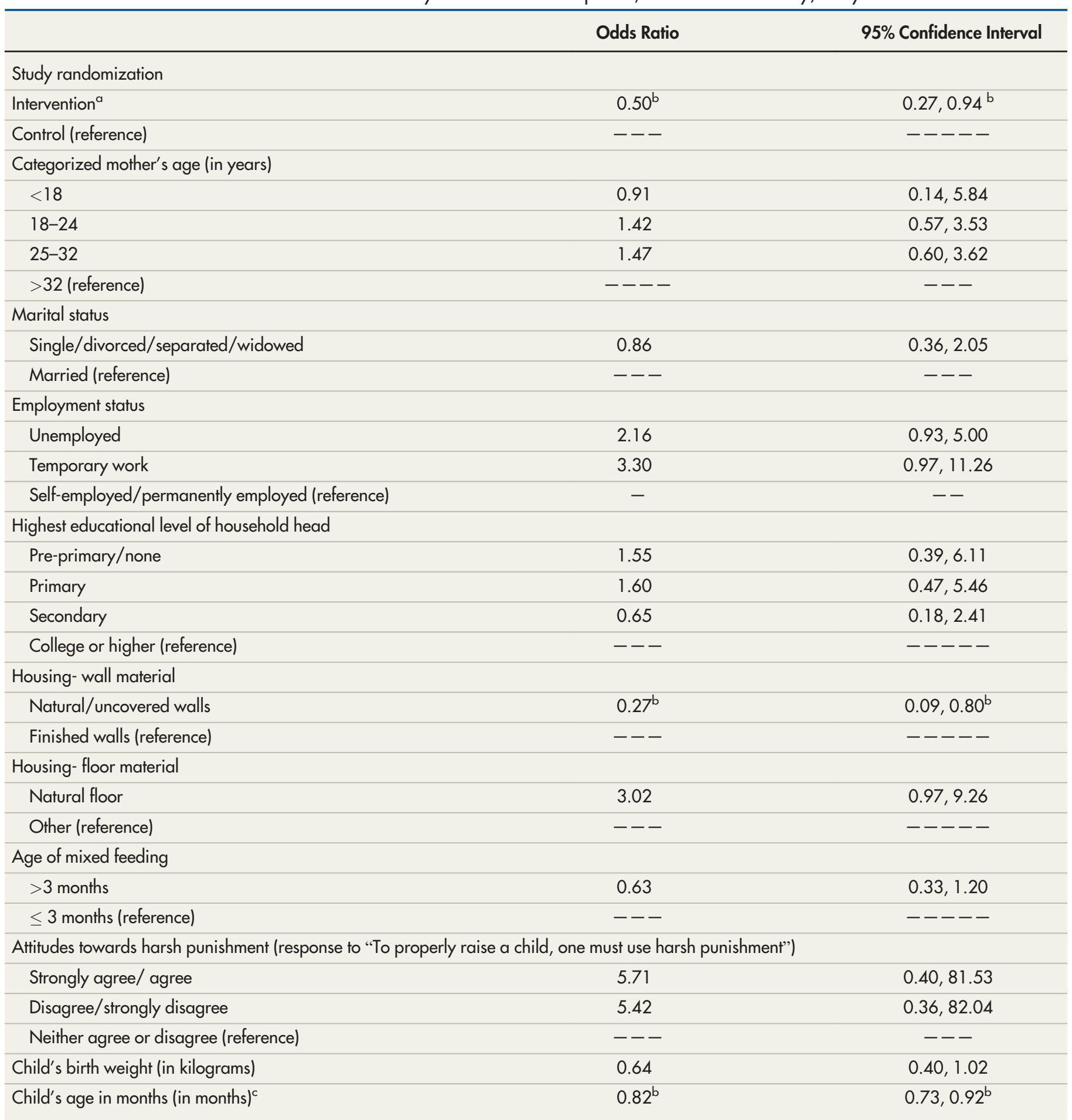

axcluded 168 subjects due to missing values for primary outcome or covariate data, with 1, 105 children remaining for analysis.

bStatistically significant with $\alpha$ set at .05.

${ }^{c}$ At the time of developmental screening questionnaire evaluation. 
of women that also engaged in microfinance activities through GISHE, this approach may have also helped mitigate important social determinants of health (e.g., inadequate funds to pay for health services). Though the latter is not a focus of this report (and will be explored in future publications), we speculate all 3 components of the model significantly contribute to its success. Our findings offer evidence to support that by addressing health, providing community, and offering a means to combat social determinants, this intervention may help protect children from developmental delays in this resource-limited setting.

It is important to note that at the point of DSQ testing, Chamas participants received limited education related to child development-focused topics, and instead, prioritized topics related to basic infant care, including proper nutrition, breastfeeding, watching for worrisome signs in the first 2 weeks of life, and the importance of setting routines, with 1 session on infant development. Interpreted in context, these findings underscore that when other factors known to impact child development are addressed, such as antenatal care attendance, facility-based delivery, exclusive breastfeeding, and adequate nutrition, rates of developmental delay may simultaneously decrease. ${ }^{16,24,38}$ This hypothesis is supported by literature from other LMICs that highlight a synergistic relationship between reinforcing positive $\mathrm{MNCH}$ behaviors and mitigating developmental delay risk. ${ }^{28,39}$ However, recent studies measured the effectiveness of 1 or 2 focused interventions on improving ECD outcomes and most have had mixed results. A recent trial that evaluated a water, sanitation, and hygiene intervention combined with nutritional counseling and supplementation in Zimbabwe demonstrated differential ECD improvement based on HIV status, with HIV-exposed children experiencing greater benefit than those uninfected. ${ }^{40,41}$ A home-based program in Pakistan that combined nutritional services and responsive caregiving training also demonstrated improvement in ECD outcomes. ${ }^{42,43}$ Very little data exist, however, on programs utilizing multiple concurrent strategies like in Chamas. As such, our findings build upon a growing body of evidence that supports MNCH strategies for mitigating developmental delay risk while also underscoring the importance of addressing its social determinants.

The rate of at-risk development was lower among infants in our cohort compared to population-based modeling estimates. Less than $4 \%$ of infants in our cohort demonstrated at-risk development, which is significantly lower than an estimated 45\% in Kenya and 43\% across LMICs. ${ }^{3,5}$ Of note, the national and international estimates of at-risk development are modeled using population data for extreme poverty and stunting as proxies for at-risk development, rather than individual-level evaluations, which generally yield greater precision. Even with more informed modeling, using data from health surveys, cohort studies, and hospital databases, the estimates of identified developmental disability in young Kenyan children is $10 \%,{ }^{44}$ which is still higher than this trial's estimate. Due to the varying definitions of at-risk development or developmental disability and the data used for modeling, it is difficult to compare those values with individual-level screening with the DSQ. When our findings are compared to other studies using the DSQ, rates of at-risk development within this study are comparable, albeit, still slightly lower than expected. These studies determined rates of at-risk development of $4.8 \%-7.3 \%$ in children under age 2 years using the DSQ. ${ }^{45,46}$ Within the DSQ validation trial in Bangladesh, $17 \%$ of children tested were identified as at-risk for developmental delays. ${ }^{26}$ Because the DSQ was administered among a myriad of other questions, the risk for response bias and interpretability of questions across different cultural contexts may complicate these results. Additional investigations, such as formative work and cognitive interviews to ensure face validity of questions, testing alongside clinical examinations, or more detailed developmental assessments, are needed to evaluate the DSQ's adequacy in identifying infants with at-risk development in this setting.

Our study found that the majority of mothers in both the intervention and control groups agreed with using physical punishment to discipline their children, although this was more common among those in the intervention group. Corporal punishment as a discipline method is associated with worse child behavioral and developmental outcomes; however, most evidence is focused on outcomes of children older than those within our cohort (i.e., aged older than 5 years). ${ }^{47-49}$ Positive parenting training is integrated within the Chamas curriculum after 2 years of program enrollment, thus study participants had minimal exposure at the time of assessment. Mothers would have relied on their prior knowledge and experiences to guide their views on physical punishment, which is very common in Kenya, ${ }^{50}$ and the higher rates of physical punishment use among the intervention group was likely incidental. The long-term impact of childhood physical punishment and parental exposure to positive parenting on ECD

\section{The majority of mothers in both the intervention and control groups agreed with using physical punishment to discipline their children, which is associated with worse child behavioral and developmental outcomes.}


should be explored within this cohort in future studies.

Aligned with current evidence, this study found that delayed introduction of mixed feeding was protective against at-risk development. Exclusive breastfeeding in the first 3-6 months of life has been associated with improved cognitive outcomes early in life; however, that benefit may not be maintained as children become school-aged. ${ }^{51-53}$ While the mechanism for this effect is unclear and likely multifactorial, ${ }^{54}$ delayed mixed feeding improves nutritional status. ${ }^{55}$ Malnutrition is a critical risk factor for worsened developmental outcomes. ${ }^{23}$ Although our analyses were limited by the absence of objective nutritional markers, we predict this adjustment would have minimally impacted our primary outcome. Children within the control group had a lower probability of poverty and, by proxy, would have been more likely to access nutritious foods. Future studies involving this cohort will work toward obtaining anthropometric measurements on study participants.

Moreover, our findings demonstrated that as the age of the child increased, the rates of at-risk development decreased. One potential explanation for this finding is related to the left-shifted or skewed distribution of age within this study cohort toward the upper end of the age range, allowing for a more reliable interpretation of the data through the model at older ages. Another potential explanation for this age-related difference is the enhanced reliability of testing in older children. The American Academy of Pediatrics recommends beginning developmental screening at 9 months, as many skills emerge by and differentiate at this age, resulting in a more reliable evaluation of developmental status. ${ }^{56}$ While less reliable, screening for at-risk development within younger aged children can be helpful to allow for those identified as having delays to be referred to appropriate therapies during the first 1,000 days of life, when they are most likely to gain the most benefit from the services. ${ }^{36}$ Longitudinal assessment of this cohort should be explored to understand the stability of developmental status over time.

An unexpected finding of our analysis was the decreased odds of at-risk development associated with uncovered or natural walls compared to finished walls. Finished walls are typically correlated with higher socioeconomic status, which has demonstrated association with improved developmental outcomes. ${ }^{33,57}$ There is evidence to suggest the quality of a child's home environment, such as the housing quality, residential mobility, and availability of learning materials, may impact
ECD. ${ }^{57,58}$ However, few studies have looked at specific housing materials, ${ }^{33}$ and none have specified an association between wall material and ECD. ${ }^{33}$ Attempting to quantify poverty status in LMICs poses significant challenges and limitations. However, tools that incorporate multiple variables to differentiate individuals on economic statuses, such as the PPI, can be helpful. While it is unclear at this time why a finding associated with higher socioeconomic status is linked with increased odds of at-risk development, we hypothesize that more complex mediators may come into play when a family has finished walls. For example, families with finished walls within their home may have 2 income-earning parents, requiring childcare for the infants. In settings like Kenya, there are limited options for high-quality, stimulating childcare, a variable for which no data were collected for this study. Another potential mediating factor may be potential exposure to lead paint, which is still used in parts of Kenya ${ }^{59}$ and is known to be associated with worse developmental outcomes. ${ }^{60}$ However, these ideas are speculative in nature and should be further explored. More delineated knowledge about household factors and their implications on child development is needed.

Our study also has notable strengths. First, by using a cluster-randomized design, we strengthen the reliability as well as contextual relevance of our results for future implementation in a community-based setting. Second, we successfully recruited and collected data on a large cohort of participants across 4 diverse sub-counties in Trans Nzoia, strengthening the generalizability of our findings. Third, by conducting an intention-totreat analysis, our findings suggest any degree of exposure to the Chamas intervention may yield protective benefits against developmental delay. This analysis approach helps simulate a realworld context where perfect program attendance is unexpected. Fourth, this cohort was sufficiently large to generate significant results in our outcome of interest. These results help strengthen our understanding of developmental delay and potentially associated risk factors in a resource-limited setting. Lastly, we used a validated questionnaire to assess ECD, which also expands upon limited data to support the utility of this screening tool in other LMICs.

\section{Limitations}

Our study has several limitations. We experienced moderate loss to follow-up rates, highlighting 
challenges in retention and data collection. Women living within rural areas of Kenya tend to be more difficult to trace for follow-up due to limited details regarding the location of their residence (i.e., no street addresses) and lack of cell phone access or cellular network coverage. Individuals who are self-employed as casual laborers must frequently move for employment opportunities. We believe these are the major reasons for lost-to-follow-up within our cohort, but more formal analysis may be required. Another limitation to this study is that the DSQ requires mothers to subjectively affirm responses to a set of observed behaviors, which risks introduction of both response and recall biases. Screening mechanisms that triangulate data from both subjectively recorded data and observed behaviors would improve the reliability of these outcomes; however, it is worth noting that these evaluations are often cost-prohibitive, particularly in resourcelimited settings. Lastly, some variables that may influence child development, such as anthropometrics and nutritional status, were not included within our follow-up evaluations due to limited trial resources. We hope future studies of this intervention will include these data to strengthen our analyses.

\section{- POLICY IMPLICATIONS AND CONCLUSIONS}

A significant advantage of the Chamas model is that it leverages existing resources (e.g., CHVs) and emphasizes collaborative investment from key stakeholders to ensure the program iteratively responds to the community's needs. While other group-based caregiver interventions have demonstrated positive results for ECD, many of these strategies introduce resource-related challenges that may compromise long-term quality and sustainability in these settings. ${ }^{61,62}$ A costeffectiveness analysis of the Chamas model was performed and found to be US $\$ 46$ per beneficiary, with both mother and infants included as beneficiaries, and would decrease to US\$33 per beneficiary if continued within the same region over time (full analysis detailed in Supplement3). Further, this analysis of DSQ data from a cluster randomized controlled trial demonstrated Chamas' potential to improve ECD outcomes. Our findings suggest this community-based intervention focused on health education for pregnant and postpartum women may support ECD as compared to the standard of care. As such, policy makers should consider the Chamas model when looking to revise current strategies to help protect children from developmental delay in this setting.

In summary, maternal participation in a community-based women's health education program was associated with lower rates of at-risk development among their children compared to the standard of care. Overall, rates of at-risk development were lower than expected for this population, warranting further investigation. Chamas may help protect children from developmental delay in rural Kenya and other resource-limited settings. Future studies are needed to clarify this association and to improve our model so that we may continue to support women and children across Kenya and in other resource-limited settings.

Acknowledgments: We thank our study participants, community health volunteers, research assistants, and staff without whom this work would not be possible. We additionally thank the sub-county and county Ministry of Health representatives in Trans Nzoia County, Kenya, for their support and collaboration. The Chamas for Change parent trial was made possible through the generous support of the Saving Lives at Birth partners: the United States Agency for International Development (USAID), the Norwegian Agency for Development Cooperation (Norad), the Bill \& Melinda Gates Foundation, Grand Challenges Canada, the U.K. Department for International Development (DFID), and the Korea International Cooperation Agency (KOICA). It was prepared by the Chamas for Change team and does not necessarily reflect the views of the Saving Lives at Birth partners or the institutions with which the authors are affiliated.

Funding: This study was made possible through the generous support of the Saving Lives at Birth partners: the United States Agency for International Development (USAID), the Norwegian Agency for Development Cooperation (Norad), the Bill \& Melinda Gates Foundation, Grand Challenges Canada, the U.K. Department for International Development (DFID), and the Korea International Cooperation Agency (KOICA) (Grant No. 0755-03). This manuscript is the work of the authors listed above and does not necessarily reflect the views of the Saving Lives at Birth partners. Megan McHenry's salary was supported by a career development award funded through the National Institutes of Mental Health (K23MH1 16808.)

Author contributions: $\mathrm{LR}, \mathrm{ACD}$, JJS conceptualized and sought funding for this study. LYM developed the protocols and data collection instruments, with oversight from LR. MSM helped select an appropriate screening tool to conduct developmental assessments for the parent trial with feedback provided by LYM and UR. GA and EK oversaw data collection activities and data management processes. All authors contributed to developing our statistical analysis plan. MSM and LYM completed the first draft of this manuscript. ZY completed all statistical analyses with significant input from MSM and LYM. All authors contributed substantially to revising this article critically for important intellectual content. All authors contributed to the final manuscript and approved submission for publication.

Data sharing: The deidentified data set and a data dictionary will be made available with publication of the trial after obtaining relevant Institutional Research Ethics Committee approval of a proposal and signed data access agreement. Inquiries can be made to co-author, Dr. Lauren Y. Maldonado (lymaldonado@mgh.harvard.edu).

Competing interests: None declared.

\section{REFERENCES}

1. Grantham-McGregor S, Cheung YB, Cueto S, Glewwe P, Richter L, Strupp B; International Child Development Steering Group.

\section{A significant advantage of the Chamas model is that it leverages existing resources and emphasizes collaborative investment from key stakeholders to ensure the program iteratively responds to the community's needs.}


Developmental potential in the first 5 years for children in developing countries. Lancet. 2007;369(9555):60-70. CrossRef. Medline

2. Early Childhood Development Overview. World Bank. Updated October 25, 2021. Accessed October 25, 2021. https://www. worldbank.org/en/topic/earlychildhooddevelopment

3. Black MM, Walker SP, Fernald LCH, et al. Early childhood development coming of age: science through the life course. Lancet. 2017;389(10064):77-90. CrossRef. Medline

4. Nurturing Care: a framework for helping children survive and thrive to transform health and human potential. Country profiles (2020). Accessed October 25, 2021. https://nurturing-care.org/resources/ country-profiles/

5. Nurturing Care for Early Childhood Development. Early Childhood Development: Kenya Country Profile. UNICEF, Countdown to 2030 Women's Children's and Adolescent's Health; 2020. Accessed October 25, 2021. https://nurturing-care.org/profiles/Kenya

6. Lindland E, Mwoma T, Owino GE, Ngutu M, Okeng'o L, Nelima D. Expanding the Basics: Mapping the Gaps Between Expert, DecisionMaker and Public Understandings of Early Childhood Development in Kenya. A FrameWorks Research Report. UNICEF, Center on the Developing Child at Harvard University, Africa Early Childhood Network; 2018. Accessed October 25, 2021. https://www. frameworksinstitute.org/wp-content/uploads/2020/05/ KenyaECDMTG-FINAL.pdf

7. Black MM, Walker SP, Fernald LCH, et al. Early childhood development coming of age: science through the life course. Lancet. 2017;389(10064):77-90. CrossRef. Medline

8. Razaz N, Boyce WT, Brownell M, et al. Five-minute Apgar score as a marker for developmental vulnerability at 5 years of age. Arch Dis Child Fetal Neonatal Ed. 2016;101(2):F1 14-F120. CrossRef. Medline

9. Bhutta AT, Cleves MA, Casey PH, Cradock MM, Anand KIS. Cognitive and behavioral outcomes of school-aged children who were born preterm: a meta-analysis. JAMA. 2002;288(6):728-737. CrossRef. Medline

10. Upadhyay RP, Naik G, Choudhary TS, et al. Cognitive and motor outcomes in children born low birth weight: a systematic review and meta-analysis of studies from South Asia. BMC Pediatr. 2019;19 (1):35. CrossRef. Medline

11. Bernard-Bonnin A-C; Canadian Paediatric Society, Mental Health and Developmental Disabilities Committee. Maternal depression and child development. Paediatr Child Health. 2004;9(8):575-583. CrossRef. Medline

12. Walker SP, Wachs TD, Grantham-McGregor S, et al. Inequality in early childhood: risk and protective factors for early child development. Lancet. 2011;378(9799):1325-1338. CrossRef. Medline

13. Chamas for Change improves mother-baby health. AMPATH. April 20, 2018. Accessed October 25, 2021. https://ampath. squarespace.com/news-blog-feed/2018/4/20/chamas-forchange-improves-mother-baby-health

14. Maldonado LY, Songok JJ, Snelgrove J, et al. Promoting positive maternal, newborn, and child health behaviors through a groupbased health education and microfinance program: a prospective matched cohort study in western Kenya. BMC Pregnancy Childbirth 2020;20(1):288. CrossRef. Medline

15. Christoffersen-Deb A, Ruhl L, Elung'at J, Atieno M, Snelgrove J, Songok J. Chamas for Change: an integrated community-based strategy of peer support in pregnancy and infancy in Kenya. Lancet Glob Health. 2015;3(S22):S22. CrossRef

16. Republic of Kenya Ministry of Health (MOH). Taking the Kenya Essential Package for Health to the Community: A Strategy for the Delivery of Level One Services (Community Health Strategy). MOH; 2006. Accessed October 25, 2021. https://www. communityledtotalsanitation.org/sites/communityledtotalsanitation. org/files/community_strategy.pdf
17. Kenya National Bureau of Statistics. Republic of Kenya Ministry of Health. Kenya National AIDS Control Council. Kenya Nationa Council for Population and Development. Kenya Medical Research Institute. Kenya Demographic and Health Survey 2014. ICF International; 2015. Accessed October 25, 2021. https:// dhsprogram.com/pubs/pdf/fr308/fr308.pdf

18. Chama Cha MamaToto: a pilot study of peer support groups in Kenya. NCT03188250. ClinicalTrials.gov. Accessed October 25, 2021. https://clinicaltrials.gov/cł2/show/NCT03188250

19. Grantham-McGregor S, Ani C. A review of studies on the effect of iron deficiency on cognitive development in children. J Nutr. 2001;131(2)(2S-2):649S-668S, discussion 666S-668S. CrossRef. Medline

20. Cordeiro CN, Tsimis M, Burd I. Infections and brain development. Obstet Gynecol Surv. 2015;70(10):644-655. CrossRef. Medline

21. Kvestad I, Taneja S, Hysing M, Kumar T, Bhandari N, Strand TA. Diarrhea, stimulation and growth predict neurodevelopment in young North Indian children. PLoS One. 2015;10(3):e0121743. CrossRef. Medline

22. Cuartas J, McCoy DC, Rey-Guerra C, Britto PR, Beatriz E, Salhi C. Early childhood exposure to non-violent discipline and physical and psychological aggression in low- and middle-income countries: national, regional, and global prevalence estimates. Child Abuse Negl. 2019;92:93-105. CrossRef. Medline

23. Walker SP, Wachs TD, Meeks Gardner J, et al. Child development: risk factors for adverse outcomes in developing countries. Lancet. 2007;369(9556):145-157. CrossRef. Medline

24. Walker SP, Wachs TD, Grantham-McGregor S, et al. Inequality in early childhood: risk and protective factors for early child development. Lancet. 2011;378(9799):1325-1338. CrossRef. Medline

25. Republic of Kenya. Ministry of Health (MOH). Division of Community Health Services. Community Health Volunteers (CHVs): Basic Modules Handbook. MOH; 2013. Accessed October 25, 2021. http:// guidelines.health.go.ke:8000/media/CHV_handbook_PDF-F.pdf

26. Khan NZ, Muslima H, Shilpi AB, et al. Validation of a home-based neurodevelopmental screening tool for under 2-year-old children in Bangladesh. Child Care Health Dev. 2013;39(5):643-650. CrossRef. Medline

27. Kenya Poverty Probability Index. Innovations for Poverty Action. Accessed October 25, 2021. https://mww. povertyindex.org/ country/kenya

28. Britto PR, Lye SJ, Proulx K, et al. Nurturing care: promoting early childhood development. Lancet. 2017;389(10064):91-102. CrossRef. Medline

29. Britto PR, Brooks-Gunn J. Provisions of learning experiences in the home and early childhood school readiness are clearly linked. New Dir Child Adolesc Dev. 2001 ;(92):1-6. CrossRef. Medline

30. Runyan DK, Dunne MP, Zolotor AJ, et al. The development and piloting of the ISPCAN Child Abuse Screening Tool-Parent version (ICAST-P). Child Abuse Negl. 2009;33(1 1):826-832. CrossRef. Medline

31. Rutterford C, Copas A, Eldridge S. Methods for sample size determination in cluster randomized trials. Int J Epidemiol. 2015;44 (3):1051-1067. CrossRef. Medline

32. Jeong J, McCoy DC, Fink G. Pathways between paternal and maternal education, caregivers' support for learning, and early child development in 44 low-and middle-income countries. Early Child Res Q. 2017;41:136-148. CrossRef

33. Bradley RH, Putnick DL. Housing quality and access to material and learning resources within the home environment in developing countries. Child Dev. 2012;83(1):76-91. CrossRef. Medline

34. United Nations Department of Economic and Social Affairs. Transforming Our World: The 2030 Agenda for Sustainable Development. Accessed October 25, 2021. https://sdgs.un.org/ 2030agenda 
35. Richter LM, Daelmans B, Lombardi J, et al. Investing in the foundation of sustainable development: pathways to scale up for early childhood development. Lancet. 2017;389(10064):103-118. CrossRef. Medline

36. Shonkoff J, Phillips D, eds. From Neurons to Neighborhoods: The Science of Early Childhood Development. National Academies Press; 2000. Medline

37. United Nations Educational, Scientific and Cultural Organization. Accountability in Education: Meeting Our Commitments. UNESCO 2017. Accessed October 25, 2021. https://en.unesco.org/gemreport/report/2017/accountability-education

38. Engle PL, Black MM, Behrman JR, et al. Strategies to avoid the loss of developmental potential in more than 200 million children in the developing world. Lancet. 2007;369(9557):229-242. CrossRef. Medline

39. Vaivada T, Gaffey MF, Bhutta ZA. Promoting early child development with interventions in health and nutrition: a systematic review. Pediatrics. 2017;140(2):e20164308. CrossRef. Medline

40. Gladstone MJ, Chandna J, Kandawasvika G, et al. Independent and combined effects of improved water, sanitation, and hygiene (WASH) and improved complementary feeding on early neurodevelopment among children born to HIV-negative mothers in rural Zimbabwe: substudy of a cluster-randomized trial. PLoS Med. 2019; 16(3):e1002766. CrossRef. Medline

41. Chandna J, Ntozini R, Evans C, et al. Effects of improved complementary feeding and improved water, sanitation and hygiene on early child development among HIV-exposed children: substudy of a cluster randomised trial in rural Zimbabwe. BMJ Glob Health. 2020;5(1):e001718. CrossRef. Medline

42. Yousafzai AK, Obradović J, Rasheed MA, et al. Effects of responsive stimulation and nutrition interventions on children's development and growth at age 4 years in a disadvantaged population in Pakistan: a longitudinal follow-up of a cluster-randomised factorial effectiveness trial. Lancet Glob Health. 2016;4(8):e548-e558. CrossRef. Medline

43. Yousafzai AK, Rasheed MA, Rizvi A, Armstrong R, Bhutta ZA. Effect of integrated responsive stimulation and nutrition interventions in the lady health worker programme in Pakistan on child development, growth, and health outcomes: a cluster-randomised factorial effectiveness trial. Lancet. 2014;384(9950):1282-1293. CrossRef. Medline

44. Olusanya BO, Davis AC, Wertlieb D, et al; Global Research on Developmental Disabilities Collaborators. Developmental disabilities among children younger than 5 years in 195 countries and territories, 1990-2016: a systematic analysis for the Global Burden of Disease Study 2016. Lancet Glob Health. 2018;6(10):e1 100el 121. CrossRef. Medline

45. Khan NZ, Shilpi AB, Sultana R, et al. Displaced Rohingya children at high risk for mental health problems: findings from refugee camps within Bangladesh. Child Care Health Dev. 2019;45(1):28-35. CrossRef. Medline

46. Uddin MZ, Rahman MM, Fatema K, Khan ASH, Hossain MM, Saad T. Status of neurodevelopmental impairments among children using rapid neurodevelopmental assessment attending a tertiary care hospital. Int J Contemp Ped. 2019;6(6):6. CrossRef

47. MacKenzie MJ, Nicklas E, Waldfogel J, Brooks-Gunn J. Corporal punishment and child behavioral and cognitive outcomes through 5 years-of-age: evidence from a contemporary urban birth cohort study. Infant Child Dev. 2012;21(1):3-33. CrossRef. Medline

48. Aucoin KJ, Frick PJ, Bodin SD. Corporal punishment and child adjustment. J Appl Dev Psychol. 2006;27(6):527-541. CrossRef

49. MacKenzie MJ, Nicklas E, Waldfogel J, Brooks-Gunn J. Spanking and child development across the first decade of life. Pediatrics. 2013;132(5):e1118-e1125. CrossRef. Medline

50. Lansford JE, Alampay LP, Al-Hassan S, et al. Corporal punishment of children in nine countries as a function of child gender and parent gender. Int J Pediatr. 2010;2010:1-12. CrossRef. Medline

51. Jedrychowski W, Perera F, Jankowski J, et al. Effect of exclusive breastfeeding on the development of children's cognitive function in the Krakow prospective birth cohort study. Eur J Pediatr. 2012;171 (1):151-158. CrossRef. Medline

52. Girard LC, Doyle O, Tremblay RE. Breastfeeding, cognitive and noncognitive development in early childhood: a population study. Pediatrics. 2017;139(4):e20161848. CrossRef. Medline

53. Horta BL, Loret de Mola C, Victora CG. Breastfeeding and intelligence: a systematic review and meta-analysis. Acta Paediatr. 2015;104(467)(S467):14-19. CrossRef. Medline

54. Belfort MB. The science of breastfeeding and brain development. Breastfeed Med. 2017;12(8):459-461. CrossRef. Medline

55. Kuchenbecker J, Jordan I, Reinbott A, et al. Exclusive breasffeeding and its effect on growth of Malawian infants: results from a crosssectional study. Paediatr Int Child Health. 2015;35(1):14-23. CrossRef. Medline

56. Council on Children With Disabilities; Section on Developmental Behavioral Pediatrics; Bright Futures Steering Committee; Medical Home Initiatives for Children With Special Needs Project Advisory Committee. Identifying infants and young children with developmental disorders in the medical home: an algorithm for developmental surveillance and screening. Pediatrics. 2006;118 (1):405-420. CrossRef. Medline

57. Ferguson KT, Cassells RC, MacAllister JW, Evans GW. The physical environment and child development: an international review. Int J Psychol. 2013;48(4):437-468. CrossRef. Medline

58. Clair A. Housing: an under-explored influence on children's well-being and becoming. Child Indic Res. 2019;12(2):609-626. CrossRef

59. Ogilo J, Onditi A, Salim A, Yusuf A. Assessment of levels of heavy metals in paints from interior walls and indoor dust from residential houses in Nairobi City County, Kenya. Chem Sci Int J. 2017;21 (1):1-7. CrossRef

60. Santa Maria MP, Hill BD, Kline J. Lead (Pb) neurotoxicology and cognition. App/ Neuropsychol Child. 2019;8(3):272-293. CrossRef. Medline

61. Kasari C, Lawton K, Shih W, et al. Caregiver-mediated intervention for low-resourced preschoolers with autism: an RCT. Pediatrics. 2014;134(1):e72-e79. CrossRef. Medline

62. Wittkowski A, Dowling H, Smith DM. Does engaging in a groupbased intervention increase parental self-efficacy in parents of preschool children? A systematic review of the current literature. J Child Fam Stud. 2016;25(11):3173-3191. CrossRef. Medline

\section{Peer Reviewed}

Received: June 24, 2020; Accepted: September 14, 2021; First published online: December 3, 2021.

Cite this article as: McHenry MS, Maldonado LY, Yang Z, et al. Participation in a community-based women's health education program and at-risk child development in rural Kenya: developmental screening questionnaire results analysis. Glob Health Sci Pract. 2021;9(4):818-831. hitps://doi. org/10.9745/GHSP-D-20-00349

(C) McHenry et al. This is an open-access article distributed under the terms of the Creative Commons Attribution 4.0 International License (CC BY 4.0), which permits unrestricted use, distribution, and reproduction in any medium, provided the original author and source are properly cited. To view a copy of the license, visit https://creativecommons.org/licenses/by/4.0/. When linking to this article, please use the following permanent link: https:// doi.org/10.9745/GHSP-D-20-00349 